\title{
Review of Learning Beyond the Classroom:
}

\section{Engaging Students in Information Literacy}

\section{through Co-Curricular Activities}

Robbie Barber

Tucker High School

Abstract: Review of Vong, S. \& Vrkljan, M. (Eds.) (2020). Learning beyond the classroom:

engaging students in information literacy through co-curricular activities. Chicago:

Association of College and Research Libraries.

Keywords: information literacy, co-curricular activities, student employment

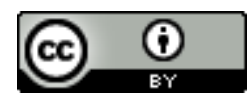

This is an Open Access article distributed under the terms of the Creative Commons Attribution 4.0 International License (http://creativecommons.org/licenses/by/4.0), which permits unrestricted use, distribution, and reproduction in any medium, provided the original work is properly cited. 
This book is a collection of articles is around the concept students must engage with information literacy outside of the classroom to really understand and use it. Co-curricular activities are the opportunities that librarians give students, or students initiate on their own, to engage and actively use information literacy. This book has four main sections: Campus connections, employment experience, innovative initiatives, and assessment approaches. While the clear focus is engaging with college students, these articles recognize that students need to carry information literacy into the "real world" and apply it in all aspects of life.

Campus Connections section has four chapters. The first two chapters describe two universities' approach to organizing competencies and learning goals. One thread that emerges from the first two chapters is the similarities in competencies and learning goals. Both programs focus on evaluating information and having students articulate their understandings. The third chapter, Taking Flight as a Campus Partner, takes its title from the University of Dayton's Housing and Residence Life, AVIATE. The librarians tied their workshops and instruction to the university's housing points. Tying into the larger university program meant that overwrought students were not perceiving that they were doing extra. The workshops were not as clearly focused on the same learning objectives found in the first two chapters. But the intercultural film studies and financial literacy workshop series allowed the library to connect to the community, advance student learning, along with information literacy. This chapter also provides a brief discussion of challenges and how to overcome them in creating similar programs. The last chapter in this section looks at using poster 
sessions to help students learn. The conclusion is that when the poster research session is driven by the library instead of a single academic entity, then the opportunities for learning are greater.

Employment Experience section reviews programs for engaging students as workers and volunteers in the campus library. While I was not a student library worker during my undergraduate days, I found myself talking to student library workers a great deal when I took my own children on tours of colleges. Each one I spoke with at more than 20 different colleges took the position because of the ease of access. But each student library worker seemed to find a great deal more value in the position than they were expecting. The chapter entitled "Library Student Employment and Educational Value Beyond the Paycheck" is my favorite in the book. The Ohio State librarian recognizes the importance of providing educational value to student workers. And, equally important, in my opinion, she includes a focus on training supervisors of student employees. I also appreciate that the chapter includes an appendix with the learning competencies for student library employees. In fact, this provides an ideal starting point to help me justify student workers in my high school library.

"On the Job Information Literacy: A Case Study of Student Employees at Purdue University Archives and Special Collections" is a case study of another student employee program. The best part of this chapter is the table that provides specific undergraduate student work activities and corresponding knowledge skills and ACRL Framework concepts. This table can be used in almost any university library program with very little changes. The 
last table in the chapter provides the graduate student work activities, knowledge skills, and ACRL Framework concepts. These two tables can be duplicated at any university setting. At the end of this chapter is a section on additional reading that allow the reader to find resources quickly and easily to get their library with engaged student workers. The last chapter in this section talks about working with student volunteers. Student volunteers run the fundraiser for the annual book sale. Running a fundraiser brings in all sorts of skill sets that students can learn including marketing, recruiting, scheduling, and managing other volunteers. Student library volunteers are often in multiple school organizations and can use their additional resources to expand the mission and information skills throughout the community. The work has purpose and meaning for the student volunteer.

Innovative Initiatives section looks at different ways to engage students in information literacy with the library. Chapter 8 introduces gaming via the library escape room. While escape rooms are fun, they can become partnerships with academic areas to create an expansive learning environment. Chapter 9 looks at identifying a gap that the library can fill. In this case, the gap is helping their international students with the English Conversation Group. Using the ACRL framework, the librarians at the University of Winsor identified a need, created a program, and gathered input from those it wished to serve. The result is a weekly service in place since 2013. Student engagement and leadership in partnership with the librarians have created a lasting effective program. 
The last three chapters of this section look at student creativity. In the chapter titled "Zines as Critical Praxis", Zines are suggested as an area of collaboration for librarians and faculty to allow students to explore beyond their classroom and share with the larger community. "Teaching Information Literacy with Civic Hacking Activities" brings students together in collaborative groups to find creative solutions to problems. The librarians at Purdue University did both short and long-term programs. The really exciting part is that undergraduate professors used these activities as part of their curriculum literally bring the classroom into the activities with the library. Co-curricular learning activities enrich both experiences. This is also true in the last chapter of the section "Exploring Service-Learning with Dance Students". While working with dance students may seem odd, the reality is that information literacy instruction occurs everywhere. In this case, working with professors who were taking a group to Panama to teach dance, gave the librarians an opportunity to talk about cultural competence and social justice. This opportunity allowed students to stay in their interest area while exploring issues that affect the greater community.

The Assessment Approaches section falls short in providing assessment direction. One chapter talks about the importance of reflection. The other chapter effectively says that there should be some sort of assessment and it should include both knowledge and social emotional learning. While that may be true, this does not really provide any new information on how to assess the impact of the material presented in the rest of the book. Fortunately, many of the programs in other chapters provided their own assessment. In the Dance chapter, 
the librarians were well aware that they had to show results from the first event in order to obtain additional funding. With that in mind, they developed pre- and post-questionnaires. The results showed an expected increase in understanding of Panama's relationship to the United States. But the unexpected results showed that students were no longer confident they were seeing implicit bias on their own. This recognition by the students allows them to incorporate information literacy into their daily lives.

This is a thin book and includes a section that, in my opinion, could have been left off. But, I recommend purchase for several reasons. One is that the different examples of engaging with students will help kickstart ideas to work in your library. We often get caught up in maintaining the things we do instead of looking for new opportunities. These articles present a variety of ways to work with students and student workers. Another important reason is the Employment Experiences section provides fully functional table of work activities, corresponding knowledge skills, and ACRL Framework concepts. Modifying these charts to fit your library will save a great deal of work and jump start your own projects. Last, I recommend reviewing the Innovative Initiatives for ideas that might engage your students. What new thing will you do with your students? 